\title{
A case study of lighting retrofit to improve building energy efficiency and lighting quality by using luminaires with nano optical coating
}

\author{
Jeffrey Y C Cheng ${ }^{1, *}$, Nancy C Y Wong ${ }^{1}$, Tony W L Ho ${ }^{1}$, Hiu Fai Kwong ${ }^{2}$, Roger T H Ng ${ }^{2}$ and Howard Cheung ${ }^{1}$ \\ ${ }^{1}$ Carbon Exchange (Hong Kong) Limited, Hong Kong, People's Republic of China \\ ${ }^{2}$ Technological and Higher Education Institute of Hong Kong, Hong Kong, People's Republic of China
}

\begin{abstract}
Lighting retrofit is a common technique to reduce lighting energy use and to improve lighting quality. It is usually performed by replacing the lamps in the existing luminaires with more efficient lamps. Despite the high potential to enhance lighting performance by improving other parts of the luminaires such as reflectors, lighting retrofits usually keep their designs unchanged and focus on the change of the lamps. In this case study, an alternative lighting retrofit method - the replacement of reflectors using a nano optical coating - was tested in a typical office in Hong Kong. The case study used a luminaire with a highly reflective nano optical coating. The pre- and post-retrofit illuminance level, illuminance uniformity, glare and lighting energy use were measured. The results show that the use of the nano optical coating enables the reduction of light tubes in the office and thus the lighting energy consumption without lowering the lighting quality. The lighting retrofit enhances the illuminance uniformity in the office by $14.6 \%$ while keeping the illuminance level and discomfort glare within the satisfactory level. It also lowers the lighting energy use of the office by $37.5 \%$.
\end{abstract}

KEYWORDS Nano optical coating; energy efficiency; lighting quality; indoor environmental quality; lighting energy use; building services CONTACT Jeffrey YC Cheng jeffrey.cheng@carbonexchange.net

Received 18 March 2020

\section{Introduction}

The demand for better lighting to improve building energy efficiency and indoor lighting quality is increasing rapidly. According to various building energy efficiency guidelines such as Leadership in Energy and Environmental Design (LEED) in the US (U.S. Green Building Council, 2019) and Building Environmental Assessment Method (BEAM) in Hong Kong (Hong Kong Green Building Council, 2012), indoor lighting should be designed to reduce lighting energy consumption in buildings by limiting lighting power density (LPD) indoors with appropriate lighting controls. Some green building guidelines such as WELL Standard (International WELL Building Institute, 2019) also specify requirements in indoor lighting quality in terms of illuminance level and colour rendering indices for a good indoor environment. These requirements are consequences of impacts of artificial lighting to climate change and building occupant comfort. Around 17\% $20 \%$ of the worldwide electricity use is consumed by artificial lighting (Zissis, 2016), and the demand of lighting in various countries can grow 1.8 - 3.5 times between 2010 and 2050 (Bergesen et al., 2015). If there is no technological advancement of lighting energy efficiency, the global temperature increase limit of $2^{\circ} \mathrm{C}$ suggested in the Paris Agreement to inhibit climate change may not be achievable (United Nations, 2015). Despite some successful cases of enhancing lighting efficiency and lighting quality simultaneously (Veitch and Newsham, 1998), there were also cases that yielded visual discomfort because of the reduction of the lighting level for energy efficiency (Hwang and Kim, 2011). While it is important to reduce lighting energy consumption, it is also important to maintain the lighting quality indoors simultaneously to satisfy people's needs. Lighting technologies should not be developed to solely enhance either lighting energy efficiency or quality alone, but for enhancement of both of them simultaneously.

Lighting energy efficiency enhancement is usually performed by technological advancement in the lamps of luminaires. In the last 15 years, the transition of lamp technologies from incandescent lamps to solid-state light emitting diodes (LEDs) has improved lighting energy efficiency significantly (Pattison et al., 2020). The increasing use of more efficient lamps has lowered the maximum LPD in the indoor environment of green buildings, and the maximum LPD in offices in multiple energy efficiency guidelines has been lowered by more than $10 \%$ in the last decade (ASHRAE, 2016; Electrical \& Mechanical Services Department, 2018). The other enhancement technology is a smart lighting control system that reduces lighting operation hours, lighting intensity and lighting energy use. Control methods such as the use of occupancy sensors and daylighting sensors are often used to automatically dim indoor lighting during unoccupied hours (ASHRAE, 2016; Electrical and Mechanical Services Department, 2018; Nagy et al., 2015). The applications of lighting diffusers (Gago-Calderón et al., 2018a) and directcurrent-network for lighting (Gago-Calderón et al., 2018b) are also investigated to enhance lighting energy efficiency. Other common methods to reduce lighting energy use include task and ambient lighting and the reduction of lighting level from the design (Dubois and Blomsterberg, 
2011).

Indoor lighting quality enhancement usually involves the maintenance of high illuminance, uniform lighting and true colour rendering (van Bommel and van den Beld, 2004). Sufficient illuminance, proper lighting direction and indoor glare removal are performed by daylighting control based on indoor lighting monitoring and simulation studies (Kruisselbrink et al., 2018). User-based designs and the control of individual lighting by task lights or smart lighting control are also recommended as good methods for lighting quality improvement (Veitch and Newsham, 1998).

A less common but effective method to enhance lighting energy efficiency and lighting quality simultaneously is the use of new lighting reflector materials. The materials have potential to enhance lighting energy efficiency by $40 \%$ through increasing the reflection of light rays from the luminaires (Dubois and Blomsterberg, 2011). Reflectors are parts of the luminaires and are used to reflect light from lamps as shown in Figure 1.

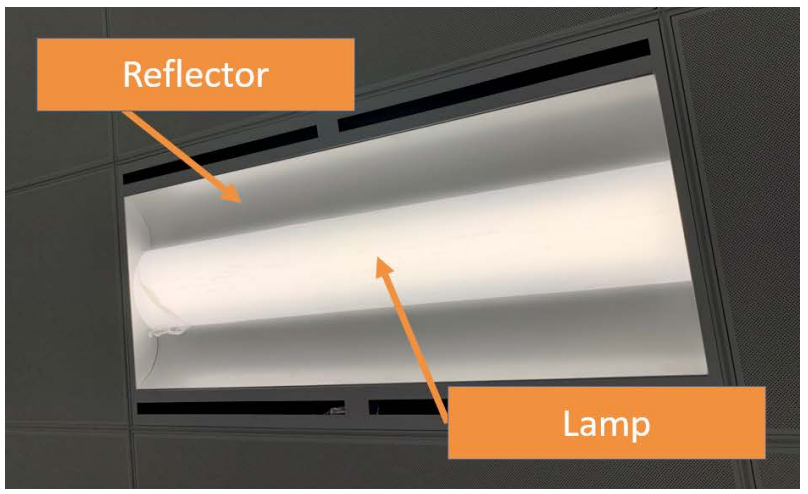

Figure 1. Illustration of a lamp and a reflector in a luminaire.

The use of highly reflective reflectors in luminaires shows significant improvement in lighting performance. The research of the application can be dated back to the 1980s which involved metal reflectors (DiLaura and Kambich, 1987). In recent years, researchers also studied the use of phosphor coating, dichoric or dielectric materials for purposes other than indoor lighting (Borbély and Johnson, 2005; Pickard and Medendrop, 2016).

While there are studies related to the use of new reflector materials for better lighting illuminance, most of them are not directly related to building energy efficiency. Examples include the use of reflective coating for solar radiation reflection from buildings (Tso et al., 2017) and solar cell efficiency enhancement (Zhong et al., 2016). Those performed for indoor lighting enhancement are not up-to-date. They involve lighting reflectors that become conventional technologies at present (DiLaura and Kambich, 1987). There should be another study on the use of state-of-the-art reflector materials to improve lighting energy efficiency and lighting quality.
To demonstrate how lighting retrofits with the stateof-the-art reflector materials improve the lighting energy efficiency and quality in buildings, this study performs a field experiment in an office building in Hong Kong. The study involves the use of a novel nano optical coating to retrofit the conventional lighting in a typical office space. The measurements of the pre- and post-retrofit illuminance level, illuminance uniformity, glare and lighting energy use of the office are studied. The differences of the metrics are compared to show the improvement of the retrofit using the new reflector materials.

\section{Method of study}

To demonstrate the enhancement of the building energy efficiency and the indoor environment quality by a lighting retrofit with a nano optical coating, a case study was performed according to the flow chart in Figure 2.

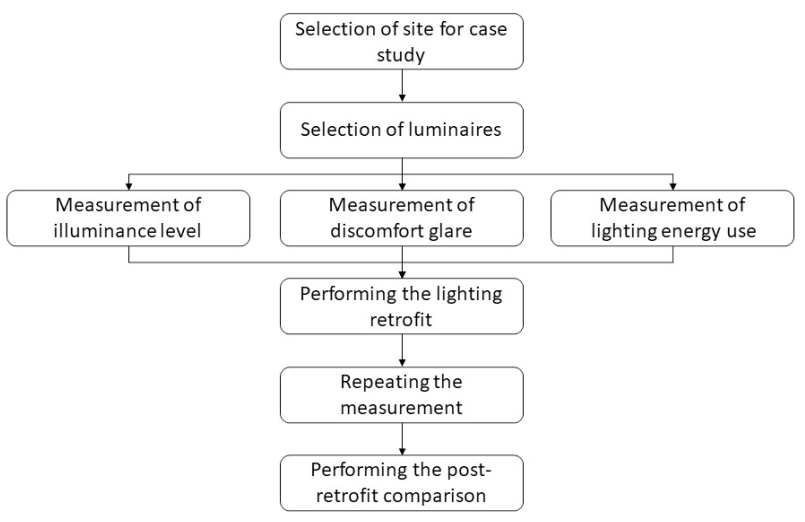

Figure 2. Case study procedures.

The case study began by selecting an appropriate test site in Hong Kong. An office with typical office settings in Hong Kong that could allow for an economical lighting retrofit would be selected to demonstrate a practical lighting retrofit scenario in Hong Kong. Measurements of the illuminance level, illuminance uniformity, discomfort glare and lighting energy use were conducted to quantify the pre-retrofit performance of the lighting installations. The retrofit was carried out by replacing the existing luminaires with the selected ones. The case study was completed by repeating the measurements and conducting the analysis for comparisons of the pre- and post-retrofit illuminance level, illuminance uniformity, discomfort glare and lighting energy use to examine the improvement brought by the lighting retrofit.

\subsection{Site selection}

The case study selected a part of an office on the ground floor of the Siu Ho Wan Government Maintenance Depot as the test site as shown in Figure 3. 
(a)

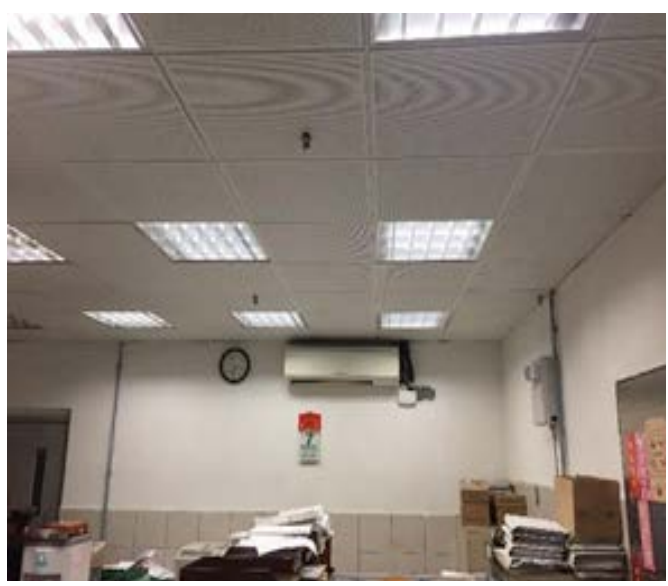

(b)

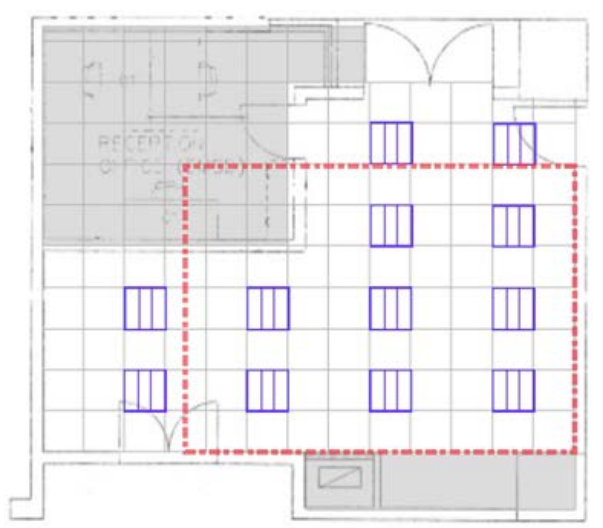

Figure 3. (a) The pre-retrofit site and (b) the selected area of the office for the case study (enclosed in a dashed line).

The office was selected because it satisfies the following criteria and represents a typical office in Hong Kong.

- The pre-retrofit site used luminaires that are widely used in Hong Kong.

- The design of lighting installations in the office (the distance between luminaires) followed that in a typical office in Hong Kong.

- The operation hours of the office followed that of a typical office.

The area of the office is $31.02 \mathrm{~m}^{2}$ with a ceiling height of $2.75 \mathrm{~m}$. The office operates from 7:30 am to $6 \mathrm{pm}$ on weekdays and Saturdays, and it closes on Sundays and public holidays. The office is mainly for screen-based work. There are 12 recessed mounted lighting trays with double parabolic metallic-finished reflectors. Each of the lighting trays has three $600 \mathrm{~mm} 14 \mathrm{~W}$ T5 fluorescent tubes as shown in Figure 4.

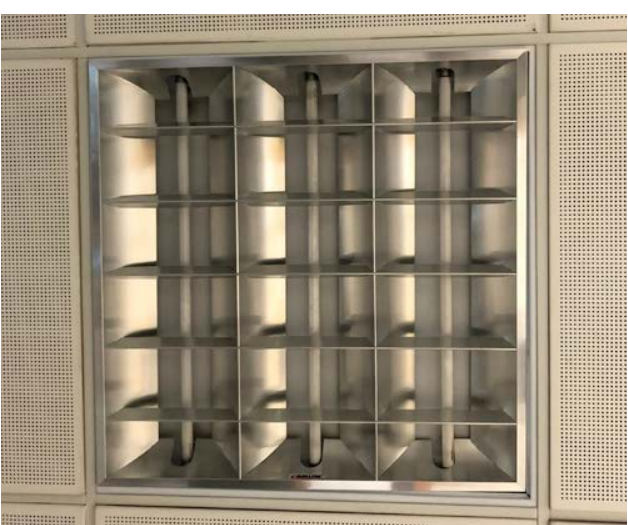

Figure 4. Luminaires installed at the site before the lighting retrofit.

In this case study, only eight recessed mounted lighting trays circled in Figure 3(b) would be retrofitted with the new ones. The other four recessed mounted lighting trays that were not involved in the case study were switched off during all measurement procedures to avoid their interference to the study.

\subsection{Selection of luminaires}

The new luminaires shown in Figure 5 were built with the same recessed mounted luminaire structure, the same dimensions and the same type of lamps as the original luminaires.

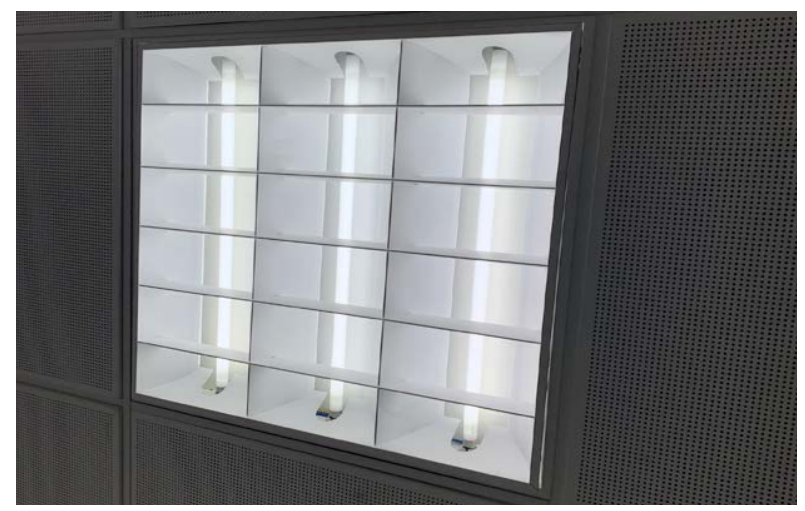

Figure 5. New luminaires with the new reflectors and the nano optical coating.

The only difference between the new and old luminaires was the double parabolic reflectors. The new luminaire reflectors were covered by a nano optical coating that consists of nano-sized metal oxide particles and exhibits a better diffuse reflection performance than their bulk counterparts (Kumar et al., 2012). The higher diffuse reflectance of the nano optical coating enabled an effective light ray reflection through not only specular reflection, but also diffuse reflection. The difference between the two modes of reflection is shown in Figure 6. 


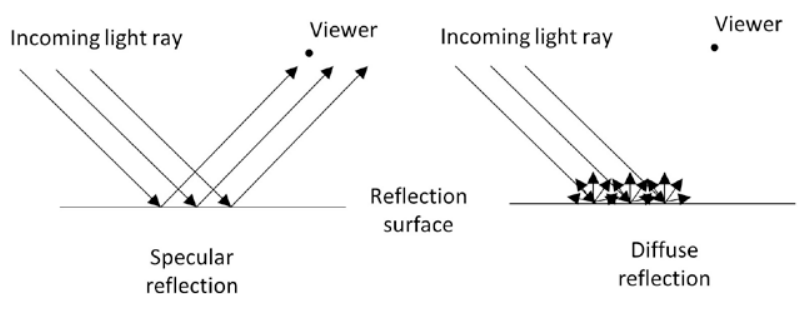

Figure 6. Specular reflection and diffuse reflection.

While direct reflection reflects light rays at the same angle as the angle of incidence, diffuse reflection reflects light rays in various directions. The high direct and diffuse reflectance of the coating enables an effective reflection of light rays. Reflectors with the coating also reflect light rays more effectively and uniformly than conventional reflectors.

\subsection{Measurement of illuminance level and illuminance uniformity}

Illuminance level measures the lighting level received by a surface, and illuminance uniformity measures the variation of illuminance on a surface. One method to maintain indoor lighting quality is to keep indoor illuminance level and illuminance uniformity above the minimum values (i.e. $300 \mathrm{~lx}$ for illuminance levels and 0.6 for illuminance uniformity in offices for mainly screenbased work) according to the function of the area to satisfy its indoor occupants (Electrical and Mechanical Services Department, 2012). In this case study, the measurement of illuminance level was taken at work-plane level, i.e. $0.8 \mathrm{~m}$ above the ground at eight locations as shown in Figure 7(a). Since the staff used computers at the site, the illuminance level at sitting eye-level $(1.2 \mathrm{~m})$ was also measured for additional reference. To select the locations of illuminance level measurement, the site was divided into 59 squares following the grid arrangement of the dropped ceiling. Every centre point of four ceiling grids was chosen as the measurement points; 27 measurement points were made as shown in Figure 7(b).

(a)

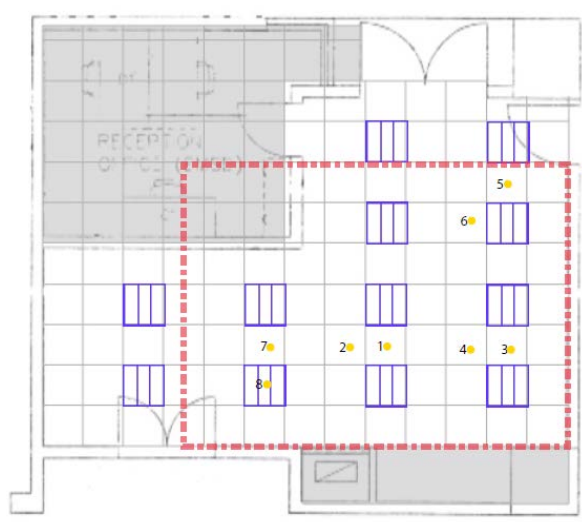

(b)

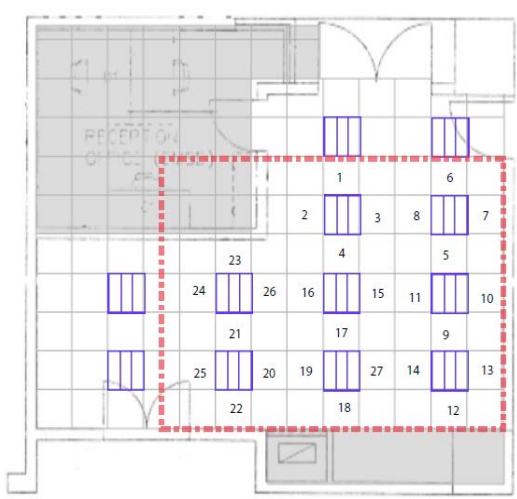

Figure 7. Measurement points (a) at work-plane level and (b) at sitting eye-level.

The measurement of each selected location was performed by a handheld lux meter (i.e. CEM DT1308 with an accuracy at $\pm 0.5 \%$ full scale). The average illuminance levels at work-plane level and sitting eye-level were calculated by averaging all the measurement points at the two levels respectively. The illuminance uniformity was quantified as the ratio of minimum to average illuminance levels in Equation (1) (Society of Light and Lighting, 2012):

$$
U=\frac{I_{\min }}{I_{a v}}
$$

where $U$ is the illuminance uniformity at the site, $I_{\min }$ is the minimum illuminance level measured at certain plane level (lx), and $I_{a v}$ is the average illuminance level at the same plane level (lx).

The illuminance uniformities at sitting eye-level and work-plane level were calculated using the data of illuminance level at each level respectively.

\subsection{Measurement of discomfort glare}

Besides indoor illuminance level and illuminance uniformity, glare is also important for building lighting quality. Glare is the sensation induced by bright areas in a person's view, and too much glare for an indoor occupant may cause discomfort and may reduce lighting quality. Discomfort glare is quantified by Unified Glare Rating (UGR) in Equation (2) (Society of Light and Lighting, 2012):

$$
\mathrm{UGR}=8 \log \left[\frac{0.25}{L_{b}} \sum \frac{L_{s}^{2} \omega}{p^{2}}\right]
$$

where $L_{b}$ is the background luminance $\left(\mathrm{cd} / \mathrm{m}^{2}\right), L_{s}$ is the luminance of the luminous parts of each luminaire in the direction of the observer's eyes $\left(\mathrm{cd} / \mathrm{m}^{2}\right), \omega$ is the solid angle of the luminous parts of each luminarie in the observer's 
eyes (sr), and $p$ is the Guth position index for each luminaire.

UGR is a measure of discomfort glare in an indoor environment. The smaller the value, the less the discomfort glare. In offices, a value above 19 indicates discomfort glare for indoor occupants (Society of Light and Lighting, 2012).

This case study utilised high dynamic range (HDR) photography to obtain the input variables in Equation (2) and thus the UGR at the site (Jacobs, 2007). The method involved the use of a camera and a chroma meter at the site. The camera was used to take pictures at various shutter speeds, and the chroma meter was used to measure the luminance level during the photo-taking processes for a reference luminance level. The vignetting effect of the camera lens was corrected in the process. The photos were synthesised digitally to create an HDR image, and the luminance level at each pixel of the photo was obtained by a calibration with a reference colour and the measured luminance level from the chroma meter. This gave the readings of $L_{b}$ and $L_{s}$ in Equation (2). The solid angle $\omega$ between the camera and the luminaires, and the Guth position index were calculated based on the geometry of the office and the luminaires, the position of the camera and the reference tables in the Lighting Handbook (Illuminating Engineering Society, 2011).

At the site, the photos and measurements were taken by positioning the camera at the midpoint of the two sides of walls in two directions - endwise (viewing direction B) and crosswise (viewing direction A) - in Figure 8 using the equipment and settings in Table 1.

Table 1. Specification of equipment for glare measurement.

\begin{tabular}{|c|c|c|}
\hline Equipment & Specification & Values and settings \\
\hline \multirow[t]{5}{*}{ Camera } & Model & Sony A6000 \\
\hline & Lens model & $\begin{array}{l}\text { SEL16F28 and Fisheye } \\
\text { converter VCL-ECF1 }\end{array}$ \\
\hline & $\begin{array}{l}\text { Equivalent focal } \\
\text { length }\end{array}$ & $16 \mathrm{~mm}$ \\
\hline & Angle of view & $\begin{array}{l}\text { Horizontal: } 99.7^{\circ} \\
\text { Vertical: } 76.4^{\circ}\end{array}$ \\
\hline & Other settings & $\begin{array}{l}\text { 1) White balance: } \\
\text { fluorescent cool white } \\
\text { 2) Image size: } 4240 \\
\text { pixels x } 2400 \text { pixels; } \\
\text { 3) Sensitivity: ISO } 100 \\
\text { 4) Aperture size: } \mathrm{f} / 2.8 \\
\text { 5) Shutter speeds } \\
: 1 / 4000,1 / 2000,1 / 1000 \text {, } \\
1 / 500,1 / 250,1 / 125 \text {, } \\
1 / 60,1 / 30,1 / 15,1 / 8, \\
1 / 4,0.5,1,2,4,8,15 \\
\text { and } 40 \text { seconds }\end{array}$ \\
\hline \multirow[t]{2}{*}{ Chroma meter } & Model & $\begin{array}{l}\text { KONICA MINOLTA } \\
\text { CS- } 150\end{array}$ \\
\hline & Accuracy & $2 \%$ \\
\hline
\end{tabular}

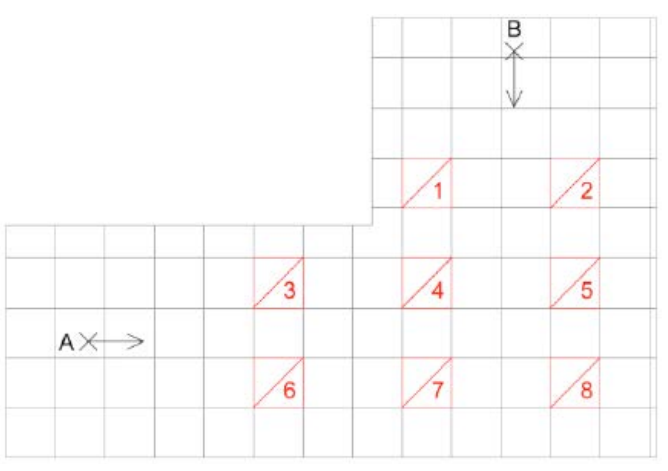

Figure 8. Viewing directions of HDR photography.

For brevity, details of the measurement and analysis method are listed in Kwong (2019).

\subsection{Measurement of lighting energy use}

The performance of lighting energy use at the site was quantified by two metrics: the daily energy consumption and the lighting power density (LPD).

The pre-retrofit daily energy consumption of the luminaires was obtained by using a clamp-on electricity meter at the subcircuit board of the lighting installations. For appropriate values of the electricity consumption of the lighting installations, the electricity consumption of the office was quantified by its average electricity consumption per working day.

LPD is a performance metric of energy use of lighting installations by Equation (3):

$$
L P D=\frac{W_{\text {total }}}{A}
$$

where $W_{\text {total }}$ is the total circuit wattage of the fixed lighting installations (W) and $A$ is the internal floor area $\left(\mathrm{m}^{2}\right)$.

LPD is commonly considered by various codes and standards (ASHRAE, 2016; Electrical and Mechanical Services Department, 2018). These codes and standards use the metric to set a maximum limit on LPD according to the nature of the indoor areas and the technology status. The power rating of the lighting installations in buildings is limited by these LPD limits and their lighting energy use is reduced. For example, the Code of Practice for Energy Efficiency of Building Services Installation sets a maximum LPD limit at $10 \mathrm{~W} / \mathrm{m}^{2}$ for offices with an internal area between $15 \mathrm{~m}^{2}$ and $200 \mathrm{~m}^{2}$ (Electrical and Mechanical Services Department, 2018).

In this case study, $W_{\text {total }}$ was calculated by summing up the wattage usage of the T5 fluorescent tubes in the luminaires and the power loss of the gears in the office area. By assuming that the power loss of the gear is $10 \%$ of the wattage usage of the light tubes, Equation (4) was used to calculate $W_{\text {total }}$ and thus its LPD: 


$$
W_{\text {total }}=n_{\text {tube }} W_{\text {tube }}(1+10 \%)
$$

where $n_{\text {tube }}$ is the total number of light tubes and $W_{\text {tube }}$ is the rated power of a light tube (W).

\subsection{Performing the lighting retrofit}

Eight luminaires in the office were replaced by luminaires with the selected nano optical coating. The locations of the replaced luminaires are bracketed in the dashed rectangle in Figure 3(b).

To study if the use of the nano optical coating in the retrofit can enhance building energy efficiency without lowering lighting quality, two extra retrofit scenarios were created by using one fewer light tube in each retrofit luminaire. One extra scenario would keep the original metal reflector, and the other one would use the reflectors with the nano optical coating. The scenarios are summarised in Table 2 .

Table 2. Conditions in different post-retrofit scenarios.

\begin{tabular}{|l|l|l|}
\hline Scenario & $\begin{array}{l}\text { No. of light tubes } \\
\text { in each luminaire }\end{array}$ & Reflector \\
\hline Scenario A & 2 & Original metal reflector \\
\hline Scenario B & 3 & $\begin{array}{l}\text { New reflector with the nano } \\
\text { optical coating }\end{array}$ \\
\hline Scenario C & 2 & $\begin{array}{l}\text { New reflector with the nano } \\
\text { optical coating }\end{array}$ \\
\hline
\end{tabular}

Scenario A was created to study the effects of ordinary retrofits by reducing the number of light tubes in the luminaires to reduce the energy use of lighting installations. Scenario B was created to study if the nano optical coating can enhance the lighting quality of the indoor environment. Scenario $C$ was created to study if the use of both measures - the reduction of the number of light tubes and the use of nano optical coating - can reduce lighting energy use without compromising the indoor lighting quality.

\subsection{Repeating the measurement after the retrofit}

The measurement of the illuminance level, uniformity and glare were repeated after the retrofit for all scenarios in
Table 2 to demonstrate the differences in lighting quality in the office due to the nano optical coating. The pre- and post-retrofit illuminance level, illuminance uniformity and UGR were compared with the corresponding requirement to examine if the retrofit brought improvement to lighting quality in the office. The daily electricity consumption and LPD of the lighting installations before and after the retrofit were compared to quantify the change of building energy efficiency due to the retrofit.

\section{Results and discussion}

\subsection{Measurement of illuminance level}

The measurement record of illuminance levels at different plane levels before and after the lighting retrofit is listed in Table 3.

Table 3 shows that illuminance level at the work-plane level in Scenario B increased by $16.6 \%$. This shows that the use of the nano optical coating can increase the illuminance level. However, at sitting-eye level, the change by the use of the nano optical coating is not significant. The illuminance level at sitting-eye level in Scenario B was only improved by approximately $3 \%$ after retrofit, and the illuminance level at sitting-eye level between Scenario A and C after retrofit only differs by approximately $3 \%$. This shows that the use of the nano optical coating in the reflector of luminaires with the design in Figure 5 has little effect to the illuminance level at sitting-eye level.

Table 3 also shows that the reduction of the number of light tubes would result in a significant reduction of illuminance level in the office, regardless of the types of reflectors used in Scenarios A and C. The illuminance level at work-plane level in Scenario A is lower than the recommended level of 300 lux in offices while the illuminance level at work-plane level in Scenario C satisfies the suggested level. This shows that the nano optical coating helps lighting retrofits where light tubes are removed to maintain the illuminance level at a satisfactory level.

\subsection{Measurement of illuminance uniformity}

The measurement of uniformities at different plane levels before and after the lighting retrofit is listed in Table 4.

Table 3. Comparison of illuminance level of the office before and after the lighting retrofit.

\begin{tabular}{|c|c|c|c|c|}
\hline \multirow{2}{*}{ Scenario } & Plane level & $\begin{array}{c}\text { Illuminance level before } \\
\text { the retrofit }\end{array}$ & $\begin{array}{c}\text { Illuminance level after } \\
\text { the retrofit }\end{array}$ & Percentage change \\
\hline \multirow{2}{*}{ Scenario A } & Sitting eye-level $(1.2 \mathrm{~m})$ & 548.7 & 380.3 & $-30.7 \%$ \\
\cline { 2 - 5 } & Work-plane $(0.8 \mathrm{~m})$ & 371.8 & 266.0 & $-28.5 \%$ \\
\hline \multirow{2}{*}{ Scenario B } & Sitting eye-level $(1.2 \mathrm{~m})$ & 548.7 & 564.0 & $+2.8 \%$ \\
\cline { 2 - 5 } & Work-plane $(0.8 \mathrm{~m})$ & 371.8 & 433.4 & $+16.6 \%$ \\
\hline \multirow{2}{*}{ Scenario C } & Sitting eye-level $(1.2 \mathrm{~m})$ & 548.7 & 368.9 & $-32.8 \%$ \\
\cline { 2 - 5 } & Work-plane $(0.8 \mathrm{~m})$ & 371.8 & 315.5 & $-15.1 \%$ \\
\hline
\end{tabular}


Table 4. Comparison of illuminance uniformity of the office before and after the lighting retrofit.

\begin{tabular}{|c|c|c|c|c|}
\hline \multirow{2}{*}{ Scenario } & $\begin{array}{c}\text { Measurement plane } \\
\text { level }\end{array}$ & $\begin{array}{c}\text { Illuminance uniformity } \\
\text { before the retrofit }\end{array}$ & $\begin{array}{c}\text { Illuminance uniformity } \\
\text { after the retrofit }\end{array}$ & Percentage change \\
\hline \multirow{2}{*}{ Scenario A } & Sitting Eye-level $(1.2 \mathrm{~m})$ & 0.62 & 0.67 & $+8.1 \%$ \\
\cline { 2 - 5 } & Work-plane $(0.8 \mathrm{~m})$ & 0.68 & 0.66 & $-2.9 \%$ \\
\hline \multirow{2}{*}{ Scenario B } & Sitting Eye-level $(1.2 \mathrm{~m})$ & 0.62 & 0.71 & $+14.5 \%$ \\
\cline { 2 - 5 } & Work-plane $(0.8 \mathrm{~m})$ & 0.68 & 0.82 & $+20.6 \%$ \\
\hline \multirow{2}{*}{ Scenario C } & Sitting Eye-level $(1.2 \mathrm{~m})$ & 0.62 & 0.71 & $+14.5 \%$ \\
\cline { 2 - 5 } & Work-plane $(0.8 \mathrm{~m})$ & 0.68 & 0.78 & $+14.7 \%$ \\
\hline
\end{tabular}

Table 5. Comparison of UGR readings and illuminance level in various retrofit scenarios.

\begin{tabular}{|c|c|c|c|c|c|}
\hline \multirow[t]{2}{*}{ Scenarios } & \multirow[t]{2}{*}{ Viewing direction } & UGR & $\begin{array}{l}\text { Illuminance level at } \\
\text { work-plane (lx) }\end{array}$ & UGR & $\begin{array}{c}\text { Illuminance level at } \\
\text { work-plane (lx) }\end{array}$ \\
\hline & & \multicolumn{2}{|c|}{ Before the retrofit } & \multicolumn{2}{|c|}{ After the retrofit } \\
\hline \multirow{2}{*}{ Scenario A } & A & 20.94 & \multirow{6}{*}{371.8} & 17.65 & \multirow{2}{*}{266} \\
\hline & $\mathrm{B}$ & 11.67 & & 12.00 & \\
\hline \multirow{2}{*}{ Scenario B } & A & 20.94 & & 19.96 & \multirow{2}{*}{433.4} \\
\hline & B & 11.67 & & 13.36 & \\
\hline \multirow{2}{*}{ Scenario C } & A & 20.94 & & 18.27 & \multirow{2}{*}{315.5} \\
\hline & B & 11.67 & & 11.80 & \\
\hline
\end{tabular}

Table 4 shows that the post-retrofit illuminance uniformity values at work-plane level in all retrofit scenarios satisfy the requirement for illuminance uniformity in offices which is 0.6 . The results also show that the illuminance uniformity was enhanced in most of the retrofit scenarios by at most $20.6 \%$ except the illuminance uniformity at workplane level in Scenario A. The illuminance uniformity at work-plane level was reduced by $2.9 \%$ after the retrofit in Scenario A but not in other scenarios with the nano optical coating. This shows that the use of the nano optical coating can improve the illuminance uniformity and offset the reduction of illuminance uniformity by a reduction of light tubes in a lighting retrofit.

\subsection{Measurement of $U G R$}

The measurement of uniformity at different viewing directions before and after the lighting retrofit are listed in Table 5.

Table 5 shows that all retrofit scenarios reduce the discomfort glare in viewing direction A and increase the discomfort glare in viewing direction $\mathrm{B}$. It also shows that the UGRs in Scenarios A and $\mathrm{C}$ are not higher than the suggested maximum UGR in offices which is 19 , and only the average illuminance levels of Scenarios B and C at work-plane level satisfy the required $300 \mathrm{~lx}$ level in offices. Only Scenario C satisfies the glare and illuminance level requirements of offices simultaneously.

\subsection{Measurement of energy consumption}

The measurement of energy consumption before and after the retrofit are shown in Table 6.

Table 6. Comparison of pre- and post-retrofit energy consumption of the luminaires.

\begin{tabular}{|l|c|c|c|}
\hline & $\begin{array}{c}\text { Measurement } \\
\text { period }\end{array}$ & $\begin{array}{c}\text { Number of } \\
\text { working days }\end{array}$ & $\begin{array}{c}\text { Average daily electricity } \\
\text { consumption on working } \\
\text { days (kWh) }\end{array}$ \\
\hline $\begin{array}{l}\text { Before } \\
\text { retrofit }\end{array}$ & $\begin{array}{c}25-31 \text { Oct } \\
2018\end{array}$ & 6 & 4.35 \\
\hline Scenario C & $\begin{array}{c}1-7 \text { Nov } \\
2018\end{array}$ & 7 & 2.72 \\
\hline \multicolumn{3}{|c|}{ Percentage difference: } & $-37.5 \%$ \\
\hline
\end{tabular}

Only the energy consumption record in Scenario $\mathrm{C}$ is used for a comparison with the pre-retrofit energy consumption record because it is assumed that only the number of light tubes in the offices affects its lighting energy consumption. The number of light tubes is kept unchanged by the retrofit in Scenario B, and its daily energy consumption should be the same as that before the retrofit. Similarly, the number of light tubes in Scenario A is the same as that of Scenario $\mathrm{C}$ after the retrofit, and its daily energy consumption should be the same as that of Scenario C.

Table 6 shows that the use of the nano optical coating can save $1.63 \mathrm{kWh}$ energy daily on average which implies an effective reduction of energy consumption of luminaires by $37.5 \%$. 


\subsection{LPD calculation}

The LPD before the retrofit is $17.87 \mathrm{~W} / \mathrm{m}^{2}$ by calculation, and the LPD in Scenario C is $13.90 \mathrm{~W} / \mathrm{m}^{2}$ according to Equation (5). As LPD is only related to the power rating of the luminaires (i.e. the number of light tubes per luminaire), only the LPD of Scenario C is used for comparison with that before the retrofit. The calculation shows that the removal of one light tube per luminaire can effectively reduce the LPD from $17.87 \mathrm{~W} / \mathrm{m}^{2}$ to $13.90 \mathrm{~W} /$ $\mathrm{m}^{2}$, but the post-retrofit LPD still exceeds the maximum limit of $10 \mathrm{~W} / \mathrm{m}^{2}$ prescribed in the BEC Code (Electrical and Mechanical Services Department, 2018).

\section{Conclusions}

This study demonstrates the effects of lighting retrofit using a nano optical coating by a field experiment in a typical office in Hong Kong. Three lighting retrofit scenarios are presented - one of them represents the conventional lighting retrofit by removing light tubes, another one replaces the existing luminaires with luminaires using a nano optical coating, and the last one involves both measures. The pre- and post-retrofit illuminance level, illuminance uniformity, discomfort glare, energy consumption of luminaires and lighting power density were measured to quantify the effects of a nano optical coating on building energy efficiency and lighting quality. The results show that the nano optical coating can effectively promote the office's illuminance uniformity by $14.5 \%$ $20.6 \%$. It also maintains the illuminance level and glare in the office at satisfactory levels after the reduction of the number of lighting tubes, unlike the ordinary lighting retrofit scenario which results in an insufficient illuminance. This lowers the office's daily lighting energy consumption by $37.5 \%$ without causing unsatisfactory lighting quality. The demonstration shows that the use of a reflective nano optical coating in lighting reflectors can improve lighting retrofits by enabling a reduction of light tubes and an enhancement of building energy efficiency without poor indoor lighting quality.

\section{Acknowledgement}

We would like to thank the Electrical and Mechanical Services Department for providing support for adoption of new technologies and necessary coordination throughout the project. We would also like to thank Dr Hilda $\mathrm{H}$ D Cheung from the Department of Building Services Engineering of The Hong Kong Polytechnic University for her support in the project.

\section{Notes on Contributors}

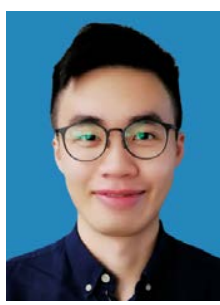

Mr Jeffrey Y C Cheng is an Energy Engineer at Carbon Exchange (Hong Kong) Limited. He graduated from The Chinese University of Hong Kong with B.Eng. (Hons) in Energy Engineering. $\mathrm{He}$ is experienced in energy management and energy system design. His research interests include energy saving technologies, smart energy and water systems.

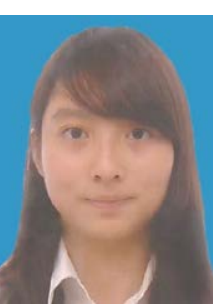

Ms Nancy C Y Wong is an Environmental Consultant at Carbon Exchange (Hong Kong) Limited. She graduated from the Hong Kong Baptist University with B.Soc. Sc. (Hons) in Geography. She is a BEAM Affiliate and is experienced in various types of environmental consultancy work such as carbon audit and green building projects. She has a research interest in environmental sustainability assessment.

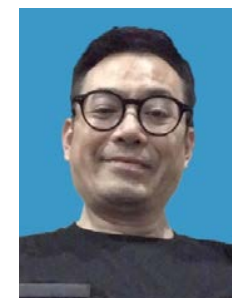

Ir Tony W L Ho is the Founder and the Director of Carbon Exchange (Hong Kong) Limited. As a professional building services engineer, he carries a solid experience in the energy and carbon management profession for over 25 years and has many relevant qualifications including Corporate Membership of The Hong Kong Institution of Engineers, Registered Professional Engineer, Registered Energy Assessor, Green Building BEAM Faculty Membership etc. He is also keen on application research in energy saving/ low carbon technologies, smart energy and water solutions. He is currently working on smart city projects and promoting green finance projects in the Greater Bay Area of the People's Republic of China.

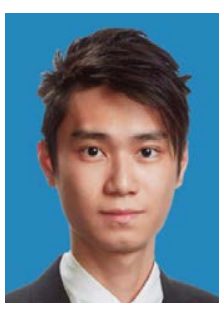

Mr Hiu Fai Kwong graduated from the Technological and Higher Education Institute of Hong Kong (THEi) with a B.Eng. (Hons) in Building Services Engineering. He worked in an energy consultancy company before pursuing further study in M.Sc. in Intelligent Building Technology and Management, The Hong Kong University of Science and Technology. His research interest is energy conservation technologies in buildings. 


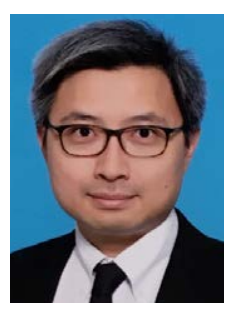

Ir Dr Roger T H Ng is an Assistant Professor and the Programme Leader of B.Eng. (Hons) in Building Services Engineering at THEi. He worked in a well-known building services consultancy firm before returning to the academic circle. His research interests include lighting engineering and sustainable buildings.

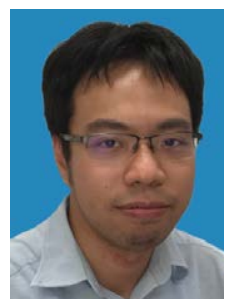

Dr Howard Cheung is a Technical and Research Manager at Carbon Exchange (Hong Kong) Limited. He graduated with his Ph.D. in Mechanical Engineering in 2014 at Purdue University, USA. $\mathrm{He}$ is a Corporate Member of the Chartered Institution of Building Services Engineers and is a Chartered Engineer of Engineering Council. His research interests include smart energy and government solutions, fault detection and diagnostics in air-conditioning equipment, and buildings and building energy data analytics.

\section{References}

[1] ASHRAE (2016). ANSI/ASHRAE/IES Standard 90.12016 Energy Standard for Buildings Except LowRise Residential Buildings. Atlanta: American Society of Heating, Refrigerating and Air-Conditioning Engineers. Inc.

[2] Bergesen JD, Tähkämö L, Gibon T and Suh S (2016). Potential Long-Term Global Environmental Implications of Efficient Light-Source Technologies. Journal of Industrial Ecology, 20, pp. 263-275.

[3] Borbély Á and Johnson SG (2005). Performance of phosphor-coated light-emitting diode optics in raytrace simulations. Optical Engineering, 44(11), pp. 111308.

[4] DiLaura DL and Kambich DG (1987). Luminaire retrofit performance: Commercial building lighting systems: Final report. California: Electric Power Research Institute.

[5] Dubois MC and Blomsterberg Å (2011). Energy saving potential and strategies for electric lighting in future North European, low energy office buildings: A literature review. Energy and Buildings, 43, pp. 25722582.

[6] Electrical and Mechanical Services Department (2018). Code of practice for energy efficiency of building services installation. Hong Kong: Electrical and Mechanical Services Department.

[7] Electrical and Mechanical Services Department (2012). Task Lighting Design. Electrical and Mechanical Services Department, Hong Kong.
[8] Gago-Calderón A, Hermoso-Orzáez MJ, De AndresDiaz JR and Redrado-Salvatierra G (2018a). Evaluation of uniformity and glare improvement with low energy efficiency losses in street lighting LED luminaires using laser-sintered polyamide-based diffuse covers. Energies, 11(4), pp. 816.

[9] Gago-Calderón A, Orejón-Sánchez RD and J Hermoso-Orzáez M (2018b). DC network indoor and outdoor LED lighting. Light-Emitting Diode - An Outlook On the Empirical Features and Its Recent Technological Advancements. London: Intechopen.

[10] Hong Kong Green Building Council (2012). BEAM Plus for New Buildings Version 1.2. Hong Kong: Hong Kong Green Building Council.

[11] Hwang T and Kim JT (2011). Effects of indoor lighting on occupants' visual comfort and eye health in a green building. Indoor and Built Environment, 20, pp. 75-90.

[12] Illuminating Engineering Society (2011). The Lighting Handbook, 10th Edition. United States: Illuminating Engineering Society.

[13] The International WELL Building Institute (2019). WELL Standard V2. New York: The International WELL Building Institute

[14] Jacobs A (2007). High dynamic range imaging and its application in building research. Advances in Building Energy Research, 1(1), pp. 177-202.

[15] Kruisselbrink T, Dangol R and Rosemann A (2018). Photometric measurements of lighting quality: An overview. Building and Environment, 138, pp. 42-52.

[16] Kwong HF (2019). Indoor lighting quality and energy implications by using advanced nanocoating luminaires. Bachelor Thesis. Technological and Higher Education Institute of Hong Kong.

[17] Kumar S, Verma NK and Singla ML (2012). Size dependent reflective properties of $\mathrm{TiO} 2$ nanoparticles and reflectors made thereof. Digest Journal of Nanomaterials and Biostructures, 7, pp. 607-619.

[18] Nagy Z, Yong FY, Frei M and Schlueter A (2015). Occupant centered lighting control for comfort and energy efficient building operation, Energy and Buildings, 94, pp. 100-108.

[19] Labour Department (2008). Lighting Assessment in the Workplace. Hong Kong: Labour Department.

[20] Pattison M, Hansen, M, Bardsley N, Elliott C, Lee K, Pattison L, Tsao J (2020). 2019 Lighting R\&D Opportunities. United States: DOE BTO Lighting R\&D Program.

[21] Pickard PK and Medendorp NW (2016). LED luminaire including a thin phosphor layer applied to a remote reflector. US9316368B2.

[22] Society of Light and Lighting (2012). The SLL Code for Lighting. Hong Kong: Chartered Institution of Building Services Engineers, pp, 36.

[23] Tso CY, Chan KC and Chao CYH (2017). A field investigation of passive radiative cooling under Hong Kong's climate. Renewable Energy, 106, pp. 52-61. 
[24] United Nation (2015). Paris Agreement. Paris: United Nations.

[25] U.S. Green Building Council (2019). LEED v4 for Building Design and Construction. United States: U.S. Green Building Council.

[26] van Bommel W and van den Beld G (2004). Lighting for work: A review of visual and biological effects. Lighting Research \& Technology, 36, pp. 255-266.

[27] Veitch JA and Newsham GR (1998). Lighting quality and energy-efficiency effects on task performance, mood, health, satisfaction, and comfort. Journal of the Illuminating Engineering Society, 27, pp. 107-129.

[28] Zhong Z, Li Ziyuan, Gao Q, Li Zhe, Peng K, Li L, Mokkapati S, Vora K, Wu J, Zhang G, Wang Z, $\mathrm{Fu}$ L, Tan HH and Jagadish C (2016). Efficiency enhancement of axial junction InP single nanowire solar cells by dielectric coating. Nano Energy, 28, pp. 106-114.

[29] Zissis G (2016). Energy consumption and environmental and economic impact of lighting: The current situation. Handbook of Advanced Lighting Technology. Switzerland: Springer, Cham, pp. 1-13. 